\title{
Tunnel Fire Simulation using FDS (Fire Dynamics Simulator)
}

\author{
Ladislav Hluchy ${ }^{1}$ \\ Institute of Informatics \\ Dubravska cesta 9, 84507 Bratislava, Slovakia \\ E-mail: hluchy.uiesavba.sk
}

\section{Ladislav Halada, Peter Weisenpacher, Jan Glasa}

Institute of Informatics

Dubravska cesta 9, 84507 Bratislava, Slovakia

E-mail: halada.uilsavba.sk, weisenpacher.uilsavba.sk, glasa.uilsavba.sk

\section{Viera Sipkova, Viet Tran}

Institute of Informatics

Dubravska cesta 9, 84507 Bratislava, Slovakia

E-mail: sipkova.uilsavba.sk, tran.ui@savba.sk

\begin{abstract}
Recent large catastrophic events, such as forest fires and fires in high buildings, car parks and tunnels, caused enormous material damages and led to tragic human lives losses. Computer simulation is one of economically least expensive and most flexible methods for getting the knowledge about fire processes under different conditions and different places or areas. The scientific research and its fire applications are very important in many countries. EU conceived several challenges to scientific institutions to enhance security against different types of fires. However, fire simulations often require high-performance computing and robust computer infrastructure which includes advanced networking and data storage systems. Therefore, Slovak National Grid Initiative (NGI) initiated new Virtual Team Project within the EGI (European Grid Infrastructure), which coveres three research teams from Slovakia, Spain and Portugal. The main goal of this project is to establish a Fire\&Smoke Simulation Virtual Research Community on EGI and to specify requirements of fire simulation applications towards EGI grid environment. From this point of view, simulation of a simple road tunnel fire scenario using Fire Dynamics Simulator FDS on cluster is discussed.
\end{abstract}

EGI Community Forum 2012 / EMI Second Technical Conference, Munich, Germany

26-30 March, 2012

$1 \quad$ Speaker 


\section{Introduction}

In the last decades, computer simulation of fire has become an efficient tool for rescue and suppression works preparation in given environment. Fire Research and Fire Engineering have grown due to continuous progress of Computational Fluid Dynamics (CFD), both in the field of theoretical modelling of physical phenomena and technological implementation of these models using complex methods and algorithms, and increasing computational power of modern computers and computing infrastructures. For certain applications, CFD and numerical heat transfer need huge computational resources, far beyond capabilities of current computers. However, not only the computational power is required for such applications. Advanced networking and data storage systems must also be available for this type of simulations. Moreover, proper parallel implementation of CFD techniques requires solution of non-trivial numerical problems. CFD simulation systems require good knowledge about fire processes and fire effects. Such systems stand usually in need of set-up of complex geometry inputs for given fire scenario, because the models at this stage do not include CAD features and do not allow automatic CAD models import. However, nowadays several support software tools are available such as graphical user interface PyroSim developed for the FDS system.

At the Institute of Informatics of Slovak Academy of Sciences (leading the Slovak NGI), there are research teams engaged in complex problems of modelling and simulation of catastrophic natural phenomena, such as floods and fires. In the field of fire simulation, we have ten years experience with forest fire simulation and simulation of fires in human structures (house fire, tunnel fire, car park fire). Such complex tasks require a deeper knowledge about simulation models and systems, and suitable high-performance computing infrastructure is inevitable. In the field of forest fire research, complex tasks related to e.g. weather modelling are also required in the phase of fire simulation inputs preparation. A group of experts is concerned with parallel and distributing computing. Their research work is directed to application of the latest intelligent high-performance computing technologies and tools in the development of new and innovation of existing scientific applications for cluster and grid computing environment. They are engaged in solving of several national and international research projects, including the EGI-InSpire [1,2].

The paper is structured as follows. In Section 2, the information about the initiation of Virtual Fire and Smoke Simulation Team and its main goals is announced. Section 3 analyses expected Virtual Team project outputs and the structure of Virtual Team. In Section 4, specific experience and expertise of Slovak research team is illustrated. Section 5 briefly summarizes the most significant assets of the presented initiative for the concerned groups of specialists, NGIs, actual EGI users and developers, as well as for the EGI Grid Infrastructure itselfand its further sustainable development.

\section{Initiation of Virtual Fire \& Smoke Simulation Team}

In December 2011, new Virtual Team (VT) project was initiated by Institute of Informatics SAS (Slovak NGI). The end of the project is assumed in June 2012. To establish an 
informal collabotation between experts on EGI grid infrastructure and perspective applicants having complex applications well-suited for the high-performance EGI infrastructure, the VT Fire Simulation Meeting was organized in February 2012.

The main goal of the Virtual Team is to create a Fire \& Smoke Simulation Virtual Research Community on EGI engaged in the fire and smoke simulation research. To solve this aim, the following actions have to be organized:

- porting the sequential and three types of parallel implementation of FDS (and other) applications to EGI

- identifying user communities for ported applications

- providing support for the communities in practical use of these applications on EGI

- further developing FDS (and other) applications based on the feedback from users.

\section{Expected VT Project Output}

The expected practical project outputs, related to FDS applications, are as follows:

- parallel implementations of FDS applications on EGI and guides for users and software administrators

- European community actively using FDS applications on EGI

- support services provided for the FDS users community in multiple NGIs.

In other words, the Virtual Team seeks to establish Fire \& Smoke Simulation Virtual Research Community on EGI and to specify requirements of fire simulation applications towards the EGI grid environment. Acquired experience may lead to future creation of a consortium prepared to apply for funded grants. Different kinds of fire simulations will be considered, such as tunel fires, fires in buildings, as well as other fire simulation applications (forest fires; the fire and smoke simulation belongs to priority topics in Mediterranean countries). The following (uncomplete) list of tasks has to be solved to obtain the project success:

- contacting fire simulation teams within the NGIs and collecting input requirements for an EGI-enabled version of FDS applications

- porting four implementations of FDS application to EGI according to the users' requirements (sequential, MPI, OpenMP and combined MPI-OpenMP application)

- implementing different simulation use cases on EGI with FDS applications and analysing simulation results with the SmokeView visualisation tool

- developing training for fire and smoke simulation communities

- developing a marketing and communication plan to undertake the outreach to fire simulation community (at their events).

There are three research groups concerned within the project coming from the NGI Slovakia, Spain and Portugal. The project was initiated under the EGI.eu administration. 


\section{Slovak Experience \& Expertise}

The Slovak research team has a long-term experience with the use of high-performance computing [11, 13, 14] for modelling and simulation of complex natural phenomena [10, 14], and about 10-year experience in the field of computer simulation of fires.

Starting with forest fire simulation [4, 5, 6, 7], we conducted a series of large-scale automobile fire tests (with single automobiles as well as with groups of automobiles) due to obtain necessary information about the course of fire and experience with fire development in different parts of automobile, as well as about the fire spread from one automobile onto a nearstanding vehicle. The fire experiments were conducted in open air, or in an experimental tunnel. Then, we simulated the fires $[8,9,16,17,18]$ using the FDS system.

Nowadays, the Slovak research team works on computer simulation of fires in closed and semi-closed areas in the framework of the research project "Research and development of new information technologies for the use of new knowledge in the field of public and environment safety" (ITMS: 26240220060). The Slovak NGI user support team provided an expertise with parallel FDS simulations on cluster.

\subsection{Fire Dynamics Simulator}

CFD models were introduced in nineties and have reached a significant development and relatively widespread use in various fields of human activity. Several advanced systems for simulation of combustion processes have been developed (e.g. CFX, PHOENICS and SMARTFIRE systems). We use FDS (Fire Dynamics System) [12]. The first version of FDS was developed by NIST (National Institute of Standards and Technology, USA) in 2000. At present, parallel versions of this program are available, what is very important for the simulation of fires in large areas, such as tunnels, car parks, shopping centers, etc. FDS is a widespread and successful system within the field of computer fire simulation. FDS provides four programming models: sequential (for single CPU), parallel MPI (for distributed memory systems), multithreading OpenMP (for shared memory systems) and combined MPI+OpenMP model (e.g. for multi-core clusters). Input data for FDS simulation are concentrated into a single (text) input file providing complete information about the given fire scenario. Simulation outputs can be written into files of various type, or visualized in the form of charts, tables, graphs, cuttings, or pictures. All output quantities and output forms must be explicitly declared in the input FDS file at the start of calculation. The visualization tool SmokeView (included in FDS package) enables to produce animations of the simulation on the screen via the simulation output.

The knowledge about automobile fires in different environments and their simulation allows us to simulate complex fire scenarios in various human structures (tunnel fire, house fire, etc.).

\subsection{Realization of short road tunnel simulation on cluster}

For purposes of this paper, the FDS simulation of a simple road tunnel fire scenario is described (see Figs. 1-2). The short (180 m long) road tunnel with two fans located on the 
tunnel ceiling in the distance of 50 and $140 \mathrm{~m}$ from the left tunnel entrance is considered. Initial fire source is represented by burning of $2 \times 3 \mathrm{~m}$ block placed in the distance of $92 \mathrm{~m}$ from the left tunnel entrance. The initial air temperature was $20^{\circ} \mathrm{C}$ and the duration of simulation was $150 \mathrm{~s}$.

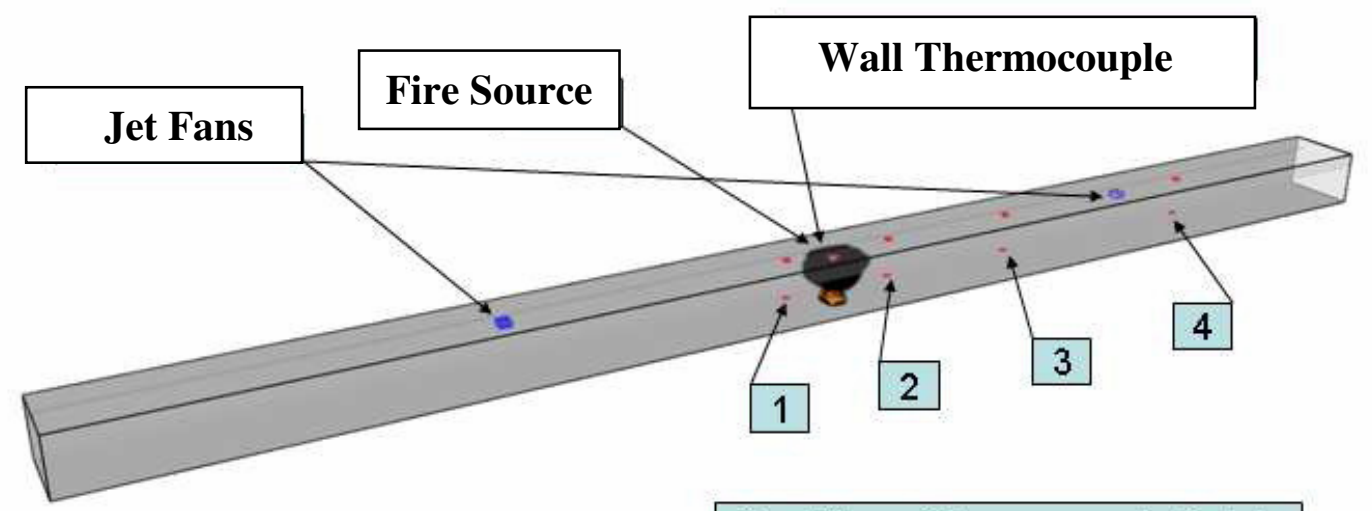

\section{Gas Phase Measurements Points}

Fig. 1 Road tunnel fire simulation

For the simulation calculation, the HP Blade Cluster (including 16 nodes with 2 quad-core CPUs, 48GB RAM, 500GB hard disk, network Infiniband) was used. To manage the processes of simulation runs, fds-manager and fds-submission scripts (written in C-Shell and PBS) were prepared. For such a short tunnel, the wall clock time of the calculation was 377.2 and 32.6 hours for sequential and parallel (24 cores used) implementations, respectively (Table 1). Impact of the computational domain decomposition on the simulation results reliability was investigated in order to select the FDS implementation with the best performance. The simulation results show that acceptable simulation precision was obtained even for the domain decompositions into large number of meshes. The MPI version of FDS implementation appears to be the most efficient. For more information about the full set of the tunnel simulations see $[16,18]$. The first successful experiments with running all FDS models on the EGI infrastructure have been performed. The submission of FDS jobs was realized using the grid middleware EMI 1 Kebnekaise [3] and the software tool MPI-Start.
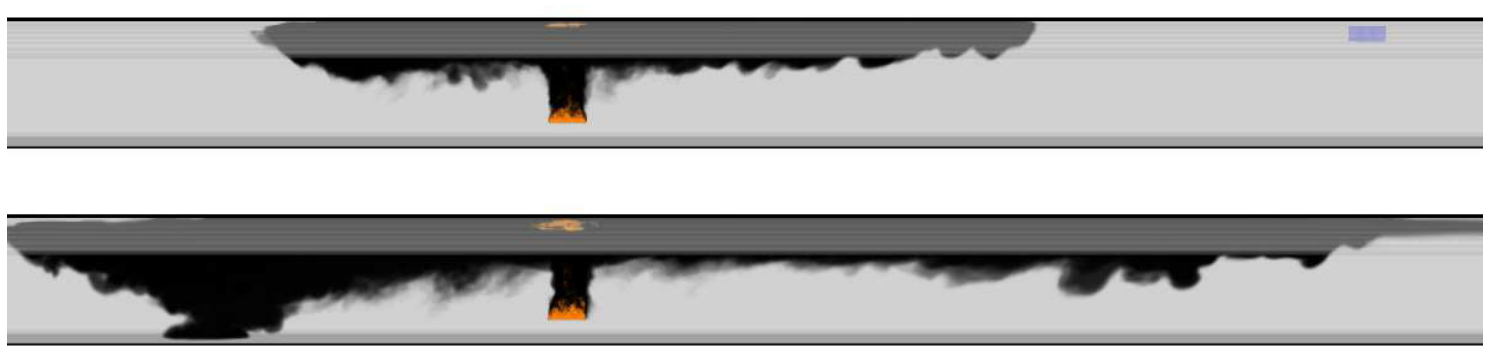

Fig. 2 Smoke development at the $50^{\text {th }}$ and $57^{\text {th }}$ second of fire 


\begin{tabular}{|l|c|c|c|c|c|}
\hline \#meshes & $\begin{array}{c}\text { \#MPI } \\
\text { proc. }\end{array}$ & $\begin{array}{c}\text { \#OpMP } \\
\text { threads }\end{array}$ & $\begin{array}{c}\text { \# Cells } \\
\text { [mil] }\end{array}$ & \#Cells/Mesh & $\begin{array}{c}\text { Wall time } \\
{[\mathbf{h}]}\end{array}$ \\
\hline 1M seq. & - & - & 12,96 & 12,96 & 377,2 \\
\hline 1M OpMP & - & 8 & 12,96 & 12,96 & 247,0 \\
\hline 8M MPI & 8 & - & 12,96 & 1,62 & 68,2 \\
\hline 24M MPI & 24 & - & 12,96 & 0,54 & 32,6 \\
\hline
\end{tabular}

Table 1. Road tunnel fire simulations results: \#meshes describes the used FDS model (sequential, MPI, OpenMPI) and number of computational meshes $(1,8,24)$; \#MPI proc. is the number of MPI processes; \#OpMP threads is the number of OpenMPI threads; \# Cells is the number of cells in millions;

\#Cells/Mesh is the number of ceel per mesh and Wall time is the total computational time in hours.

\section{Conclusion}

In this paper, new initiative of the Slovak NGI related to the Virtual Team Project is presented. The project aims to establish Fire \& Smoke Simulation Virtual Research Community on EGI and follows the significant requirements of the fire research community to solve complex fire scenarios on robust high-performance computing infrastructure. The main goals and the corresponding relevant activities which will have to be organized, as well as the expected Virtual Team outputs are listed and commented.

The Slovak research team has about 10-years experience with term experience in the field of computer simulation of fires. It consistes of specialists on computer simulation of fires by Fire Dynamics Simulator (FDS) supported by the Slovak NGI providing an expertise with parallel FDS simulations on cluster.

An example of the FDS simulation of a short $180 \mathrm{~m}$ long road tunnel fire scenario and its realizations using different FDS models on the HP Blade Cluster (included in EGI) is illustrated. The total computational time varies from $377,2 \mathrm{~h}$ (for sequential case) to 32,6 $\mathrm{h}$ (for 24-node cluster case). However, the length of typical road tunnels is more than $1 \mathrm{~km}$ and such simulations require robust, high-performance computational environment.

We are convinced that the proposed Virtual Team Project goals are in accordance with the EGI long-term evolution strategy to increase the diversity and quality of users and communities exploiting the infrastructure for world class research. The project aims to enable complex FDS (and other) fire applications to use the existing middelware services and existing high-level frameworks and tools on EGI and to identify possibly required extentions of existing middelware and community software services within the NGIs and active fire communities users in order to support new high-level applications and use cases on EGI. The goal is to achieve improved usage of the existing EGI infrastructureand to deliver new services that help EGI diversify its user base. We are convinced that the fire research community is a special community having complex computational applications with urgent need to be initiated and run 
by EGI. The Virtual Team Project will make available specific well-defined needs of the community that need to be supplied and that are aligned to the strategic goals of the EGI community.

EGI can provide an infrastructure and technical support for fire related applications. However, the fire research community needs

- sustainable

- high-performance

- reliable, and

- failure-free

computing infrastructure and storage resources. Our initiative can also become a small contribution to the development of long-term evolution EGI strategy and anticipating a significant increase of diversity and quantity of users and communities exploiting the EGI infrastructure. The acquired experience may also lead to future creation of a consortium prepared to apply for funded EU projects.

\section{References}

[1] EGI (European Grid Infrastructure), http://www.egi.eu/

[2] EGI-InSPIRE project (Integrated Sustainable Pan-European Infrastructure for Researchers in Europe). http://www.egi.eu/about/egi-inspire/index.html

[3] EMI (European Middleware Initiative). http://www.eu-emi.eu/

[4] J. Glasa, L. Halada, On mathematical foundations of elliptical forest fire spread model, Chapter 12, pp. 315-333, Forest Fires: Detection, Suppresion and Prevention (E. Gomez, K. Alvarez, eds.), Nova Science Publishers, New York, 2009, 350 p.

[5] J. Glasa, P. Weisenpacher, L. Halada, Tragic forest fire in Slovak Paradise: ten years after. Proc. of the Int. Conf. on Forest Fire Research (D. X. Viegas, ed.), Coimbra, 2010, 15 p.

[6] L. Halada, J. Glasa, P. Weisenpacher, Computer forest fire simulation as a tool for fire progress prediction and back analysis of fire origin, Proc. of the Int. Conf. on Emergency, Rescue-Securex and Pyropol Technology, Bratislava, 2009, pp. 29-34.

[7] L. Halada, P. Weisenpacher, J. Glasa, Computer modelling of automobile fires, Chapter 9, Advances in Modeling of Fluid Dynamics (Ch. Liu, ed.), InTech 2012, pp. 203-228.

[8] L. Halada, P. Weisenpacher, J. Glasa, Reconstruction of the forest fire propagation case when people were entraped by fire, Forest Ecology and Management, Vol. 234S, 2006, pp. 127.

[9] L. Halada, P. Weisenpacher, G. Oksa, J. Glasa, M. Becka, Computer based simulation of fires in risk areas (Invited lecture), Proc. of the 9th Int. Conf. on Fire Protection (FIRECO 2011), Trencin, 2011, pp. 93-102.

[10] L. Hluchy, T. G. Nguyen, L. Halada, V. D. Tran, Cluster computation for flood simulations, High-performance computing and networking, Lecture Notes in Computer Science, Berlin Heidelberg Springer-Verlag, Vol.2110, 2001, pp. 425-434. 
[11] G. Lecca, M. Petitdidier, L. Hluchy, M. Ivanovic, N. Kussul, N. Ray, V. Thieron, Grid computing technology for hydrological applications, Journal of Hydrology, No. 403, 2011, pp. 186-199.

[12] K. McGrattan, R. McDermott, S. Hostikka, J. Floyd, Fire Dynamics Simulator (Version 5), User Guide, NIST, 2010, 221 p.

[13] E. Pajorova, L. Hluchy, Visualization the Natural Disasters Simulations Results Based on Grid and Cloud Computing. Emerging Informatics - Innovative Concepts and Applications, InTech 2012, pp. 85-100.

[14] E. Pajorova, L. Hluchy, L. Halada, Visualization service for grid-oriented applications of natural disasters. Environmental economics and investment assessment II. (K. Aravossis, C.A. Brebbia, N. Gomez, eds). WIT Press, 2008, pp. 105-114.

[15] U. Schwiegelshohn, R. M. Badia, M. Bubak, M. Danelutto, S. Dustdar,F. Gagliardi, A. Geiger, L. Hluchy, D. Kranzlmuller, E. Laure, T. Priol, A. Reinefeld, M. Resch, A. Reuter, O. Rienhoff, T. Ruter, P. M. A. Sloot, D. Talia, K. Ullmann, R. Yahyapour, Perspectives on grid computing: Future Generation Computer Systems: The International Journal of Grid Computing - Theory Methods and Application, Vol. 26, Iss. 8, 2010, pp. 1104-1115.

[16] P. Weisenpacher, J. Glasa, L. Halada, Computer simulation of automobile engine compartment fire, Proc. of the Int. Congress on Combustion and Fire Dynamics, Santander, 2010, pp. 257-270.

[17] P. Weisenpacher, L. Halada, J. Glasa, Computer simulation of fire in a tunnel using parallel version of FDS, Proc. of the 7th Mediterranean Combustion Symposium, Associazione Sezione Italiana del Combustion Institute, 2011, 11 p.

[18] P. Weisenpacher, L. Halada, J. Glasa, V. Sipkova, Parallel model of FDS used for a tunnel fire simulation, Proc. of the Int. Conf. ParNum 2011, Graz, 2011, pp. 96-105.

Acknowledgement. This work was supported by Operational Programme Research \& Development funded by the ERDF (Research and development of new information technologies for forecasting and solving crisis situations and public safety, ITMS 26240220060). 